\title{
A Chef's Perspective on Potatoes and Diet
}

\author{
Leif Benson ${ }^{1}$
}

Published online: 28 March 2019

(C) The Potato Association of America 2019

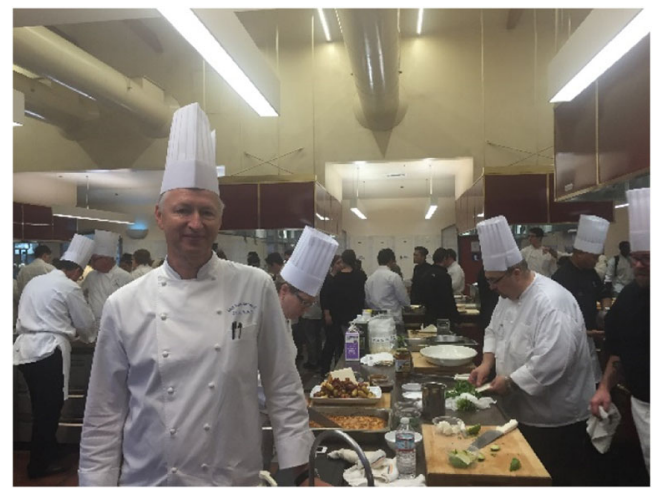

Commentary by Leif Benson CEC, AAC

Chef Emeritus

International Culinary Ambassador

Today we live in a food centric world. Chefs are pushing their creative powers to produce more exciting dining experiences. Millennials, consumers, bloggers and food enthusiasts are looking for the next new food experience and are willing to pay for a picture-worthy plate to post of their favorite dish on social media. Potatoes are valued by all cuisines for their versatility, satisfying flavor, adaptability and affordability. They store well, are nutritious and are important parts of most diets. Chefs value potatoes for their unique role in the culinary world; they often refer to them as a blank palette for creativity.

In Europe a greater variety of potatoes are available in stores, and varieties are prized for their differences and specific culinary qualities. Unlike in the United States, where consumers generally don't shop for a specific potato variety, in Europe special varieties are celebrated for their use in a specific dish. Many varieties are rarely seen in the US aside from heirloom gardeners who grow and sell them from their homes and farmer's markets. From a chef's point of view, US grocery stores do not promote

Leif Benson

leifbenson1@gmail.com

1 Oregon Department of Agriculture, Oregon, USA

or devote enough shelf-space to more unique potato varieties that have wonderful flavors, textures and colors, many of which have excellent nutritional value and elevated levels of antioxidants.

The next generation, Gen- Z kids, will have grown up in this foodie-focused world and are being influenced by their parents and media for what should be important to them. Retail stores and the overall industry must respond to their priorities, concerns and ultimately their purchasing decisions.

We all want the best food for our children and potato-based dishes are some of the most popular with our kids. Although French fries lead the way, healthier alternatives such as oil free frying could be an option for many; the technology is there, but has not become mainstream yet. The school lunch program is very important to many families, and potatoes should be a part of a balanced diet. Menu planners, nutritionists and chefs must provide recipe guidelines for optimum dishes that utilize potatoes in creative, delicious and affordable ways. It's possible that we have fallen into a rut that potatoes must become French fries in order for kids to want them in school; that's one reason it has become a negative agent in the minds of some. But what if we make French fries into a healthy option for kids and adults? It's relatively simple to use heart smart methods of preparation and seasoning alternatives that are delicious and modest in calories.

Obesity among children continues to be on the rise and potatoes are often getting a bad rap, especially French fry consumption. Chefs today are more educated than ever in understanding the challenges of good nutrition for kids. School lunches are just one element of daily consumption. Home meals and snacks are often where the real issues reside. Potatoes can be our nutritional friends; it's all about preparation of our spuds.

There are many options to prepare potatoes in a sound, healthful and delicious way. Better oils and less use of fats, and more use of seasonings is often a good direction that yields great results and can be just as satisfying. Boiling potatoes in flavorful stocks boost palette satisfaction while adding no additional fats. An important point is that potatoes in their native form are a low-calorie food; in the absence of high-calorie additives, potatoes are not high in calories. As discussed later in this issue, consuming one pound of potatoes 
would be very filling for many people, but would provide only about 440 cal.

In keeping with consumer trends, today's chefs are looking for big flavor in small bites. Small potatoes (also known as baby or new potatoes) play a big role in some of today's trendy restaurants and are great for tapas and shared plates. They have great visual value, higher amounts of phytonutrients, and many, such as fingerlings and marble potatoes, have excellent taste with snappy skins.

Power Bowls continue their meteoric rise, and potato dishes are finding their ways into bowls topped with as many exciting toppings as chefs can imagine. Potatoes are the foundation of some of the most satisfying power bowls of this big food trend. While it is tempting to dismiss the opinions of chefs, in today's food-focused culture, consumers often seek out menu ideas from celebrity chefs via the Food Network and the internet. Chefs are playing a larger role in shaping and influencing what consumers are looking for regarding special and everyday meals.

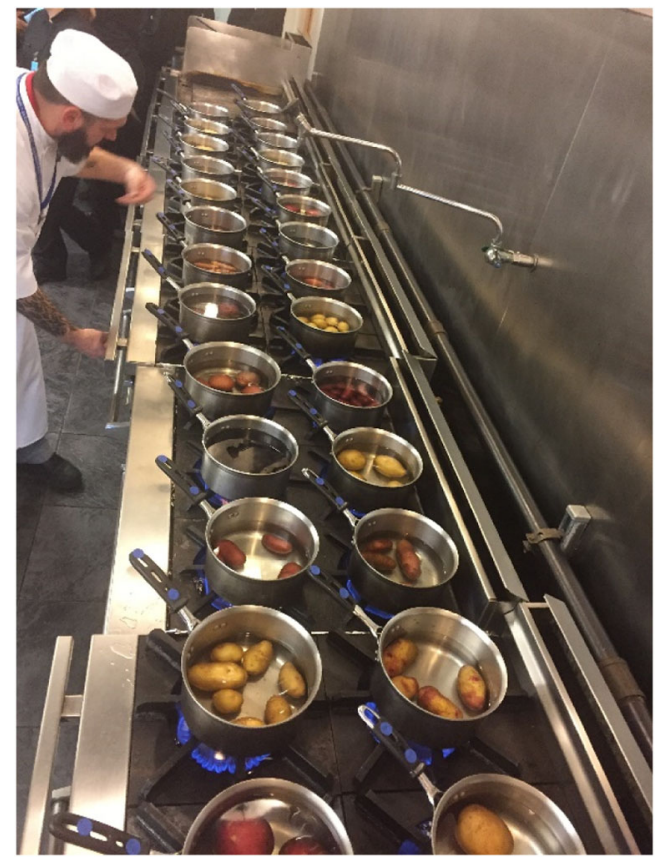

Globally, flavors are playing a major role in food trends. Chefs have been working with Oregon State University's potato breeding program, and in recent years have conducted potato sensory evaluations at Le Cordon Bleu with a panel of skilled food professionals to help select Oregon's best potato in several categories including red, yellow russet and specialty varieties as well as several experimental entries. The chefs always comment on the surprising differences in textures and flavors when comparing the same variety grown in different areas and soil types in the state.

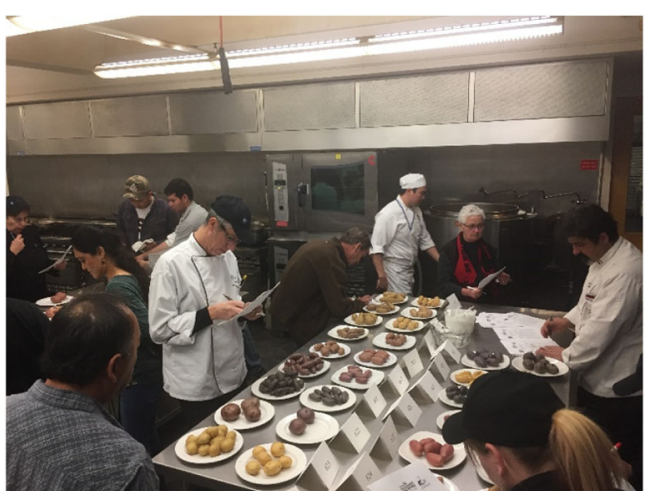

Potato culinary qualities are beginning to play a bigger role in plant breeding. Chefs believe that potatoes should be selected based on flavor and nutrition as well as yield, storage, shipping ability, uniformity and disease resistance. Bland potato varieties with poor culinary qualities are not ideal in the foodie world. We should not underestimate the importance of bold potato flavor. There are more than 4000 varieties of native potatoes found mostly in South America; researchers could seek out delicious potato flavors and nutritional values from heirloom varieties to capitalize on the impact that big flavor and health brings to the table. Food writers often ask when tasked with writing about spuds "what's new with potatoes?" Maybe the next thing could be: Potatoes go viral for delicious flavor, nutritional value and are modest in calories.

Of course, farmers are driven by consumer demand and pricing, and it is a big challenge to introduce new varieties without an established market. Chefs can help drive market demand when they are excited about a new experience for their customers. Modern chefs will often feature on their menus farms, potato and vegetable varieties and anything of interest where customers will take note and capture that image on their smartphones. There are many opportunities to brand farm or potato varieties that are purchased by restaurants. Many chefs enjoy identifying the farm or specific variety of produce that they work with in developing their current menu ideas. Developing the relationship is what the Farm to Table movement is all about.

Great food, friends and family are an essential part of everyday life! As consumers express interest in potatoes driven by chefs who love to create tasty recipes, perhaps through social media and education chefs can build the next power dish with potatoes providing great nutrition and culinary satisfaction. The potato industry and chefs should take advantage of the foodie enthusiasm generated by millennials to show them just what flavors, textures and nutritional value potatoes are truly capable of. They are nutrient dense complex carbs, fuel for your brain, a key source of energy for muscles and important for optimal mental and physical performance. 